Short Communication

\title{
Nickel Oxide Decorated Carbon Nanofibers as High Performance Electrodes for Supercapacitors
}

\author{
Lin Lihua ${ }^{1, *}$, Shi Juanli ${ }^{1}$, Liao Xiaoqun ${ }^{2}$ \\ ${ }^{1}$ Department of telecommunication and Information Engineering, Xi' an University of Science and \\ Technology, Xi'an 710054, China \\ ${ }^{2}$ Information and Network Center, Xi' an University of Science and Technology, Xi'an 710054, China \\ "E-mail: $\underline{407123402 @ q q . c o m}$
}

doi: $10.20964 / 2019.03 .13$

Received: 5 November 2018 / Accepted: 27 December 2018 / Published: 7 February 2019

Hollow carbon nanofibers (HCF) are excellent electrode materials for the supercapacitors in the energy storage area. In this work, hollow carbon nanofibers are prepared firstly. After that, nickel oxide (NiO) nanoparticles are uniformly decorated in HCF (N@HCF) as high performance electrodes for supercapacitors. The electrochemical results indicate that the specific capacity value of $\mathrm{N} @ \mathrm{HCF}$ electrodes is $832 \mathrm{~F} \mathrm{~g}^{-1}$ at the current density of $1 \mathrm{~A} \mathrm{~g}^{-1}$. Moreover, the N@HCF electrodes show perfect rate performance and superior cycle stability.

Keywords: HCF; N@HCF; Specific Capacity; Electrochemical Performance

\section{FULL TEXT}

(C) 2019 The Authors. Published by ESG (www.electrochemsci.org). This article is an open access article distributed under the terms and conditions of the Creative Commons Attribution license (http://creativecommons.org/licenses/by/4.0/). 